\title{
Mechanical Ventilation Alarms and Alarm Fatigue
}

\author{
J Brady Scott, Laura De Vaux, Connie Dills, and Shawna L Strickland
}

\author{
Introduction \\ Search Strategy \\ Why Is This a Problem? \\ Issues With Setting Alarm Limits \\ Issues With Audible Alarms \\ Negative Impact of Noise \\ Factors Contributing to Alarm Fatigue \\ Recommendations for Future Research
}

\begin{abstract}
Mechanical ventilation alarms and alerts, both audible and visual, provide the clinician with vital information about the patient's physiologic condition and the status of the machine's function. Not all alarms generated by the mechanical ventilator provide actionable information. Over time, clinicians can become desensitized to audible alarms due to alarm fatigue and may potentially ignore an actionable situation that results in patient harm. Alarm fatigue has been recognized by multiple agencies as a major patient-safety issue. To date, mechanical ventilator alarm settings do not have standardized nomenclature. The aim of this review was to examine and report on the literature that pertains to mechanical ventilation alarms and alarm fatigue and to propose recommendations for future research that may lead to safer mechanical ventilation alarm practices. Key words: mechanical ventilation; ventilator alarm; patient safety; alarm fatigue; alarms. [Respir Care 2019;64(10):1308-1313. ㅇ 2019 Daedalus Enterprises]
\end{abstract}

\section{Introduction}

Mechanical ventilation alarms, including both invasive and noninvasive mechanical ventilation, provide both au-

\footnotetext{
Mr Scott is affiliated with Rush University, Chicago, Illinois. Ms De Vaux is affiliated with Yale New Haven Hospital, New Haven, Connecticut. Ms Dills is affiliated with Vyaire Medical, Hartford, Connecticut. Dr Strickland is affiliated with the American Association for Respiratory Care, Irving, Texas.

Supplementary material related to this paper is available at http:// www.rcjournal.com.

Mr Scott has disclosed a relationship with Ventec Life Systems. Ms De Vaux has disclosed no conflicts of interest. Ms Dills was employed at the Hospital for Special Care in New Britain, Connecticut, during the majority of the manuscript preparation. Dr Strickland has disclosed no conflicts of interest. The authors are members of the AAMI Foundation's Ventilator Alarms Management Workgroup; Dr Strickland serves as chair of this workgroup.
}

dible alarms and non-audible visual alerts designed to ensure safe mechanical ventilatory support by notifying the clinician of changes in a patient's status. Clinicians can set parameters that warn of device malfunction or changes in a patient's condition. ${ }^{1}$ Not all audible alarms generated by the mechanical ventilator require an action from the clinician, and such alarms may be silenced or ignored. The true value of mechanical ventilation alarms may be lost in the sheer quantity of competing alarms commonly found in today's ICU environment, such as intravenous pump alarms, feeding system alarms, and physiologic monitor alarms. It has been reported that there are $>150$ alarms

\footnotetext{
Correspondence: Shawna L Strickland PhD RRT RRT-NPS RRT-ACCS AE-C FAARC, 9425 N. MacArthur Blvd., Suite 100, Irving, TX 75063. E-mail: shawna.strickland@aarc.org.
}

DOI: $10.4187 /$ respcare.06878 
per patient, per day in an ICU, and many of these alarms (85-99\%) do not require clinical intervention. ${ }^{2}$ Beyond alarms from other devices, mechanical ventilators themselves have a plethora of alarm features and alarms sounds, some of which vary by priority, and all of these alarms can contribute to alarm fatigue.

A 2014 report produced by the Association for the Advancement of Medical Instrumentation identified challenges regarding mechanical ventilation alarm. ${ }^{3}$ Notably, some alarm systems do not properly distinguish lifethreatening (ie, actionable) alarms from nuisance (ie, nonactionable) alarms. The report also noted that alarm parameters can be easily set incorrectly, alarm signal delays may be inadequate, and the communication of alarms to clinicians may be problematic. ${ }^{3}$

The challenge in determining proper alarm settings for accurately monitoring the patient's condition is not a new phenomenon. ${ }^{2,3}$ It is not clear why this topic has received so little attention, although it could be due to the tremendous variability in technology, patient and practitioner factors, and environment of care (eg, ICU, long-term acute care, skilled-nursing facility, transport, home). The issues with setting alarms incorrectly can also result in alarms that fail to activate. Kun et $\mathrm{al}^{4}$ identified that low-inspiratory pressure alarms of home mechanical ventilators were insufficient to identify major actionable issues, such as decannulation with smaller tracheostomy tubes. Sterni et $\mathrm{al}^{5}$ recommend physiologic monitoring of pediatric patients requiring chronic home ventilation, citing small studies that suggest these alarms may not function correctly. Although there is no doubt that mechanical ventilation alarms are important, there is a clear need for improvement.

Alarm fatigue is a phenomenon that occurs as clinicians become desensitized to audible alarms due to their large numbers and omnipresence in the ICU. Several studies have reported on the burden of audible physiologic alarms, many of which are nonactionable. ${ }^{6-11}$ This overexposure to nonactionable alarms results in decreased alertness and lower confidence in the accuracy and urgency of audible alarms. ${ }^{12}$ Alarm fatigue has been recognized as a patient safety issue by organizations such as The Joint Commission, the ECRI Institute, and The Healthcare Technology Foundation. In 2014, The Joint Commission included alarm safety as a National Patient Safety Goal.,2,13 Although several years have passed since the addition of this National Patient Safety Goal, the ECRI Institute named improperly set ventilator alarms as the \#4 health hazard of the 2019 Top 10 Health Technology Hazards list. ${ }^{14}$

The purpose of this review was to examine and report on the literature that pertains to mechanical ventilation alarms and alarm fatigue. In addition, recommendations for future research that may lead to safer mechanical ventilation alarms practices have been made.

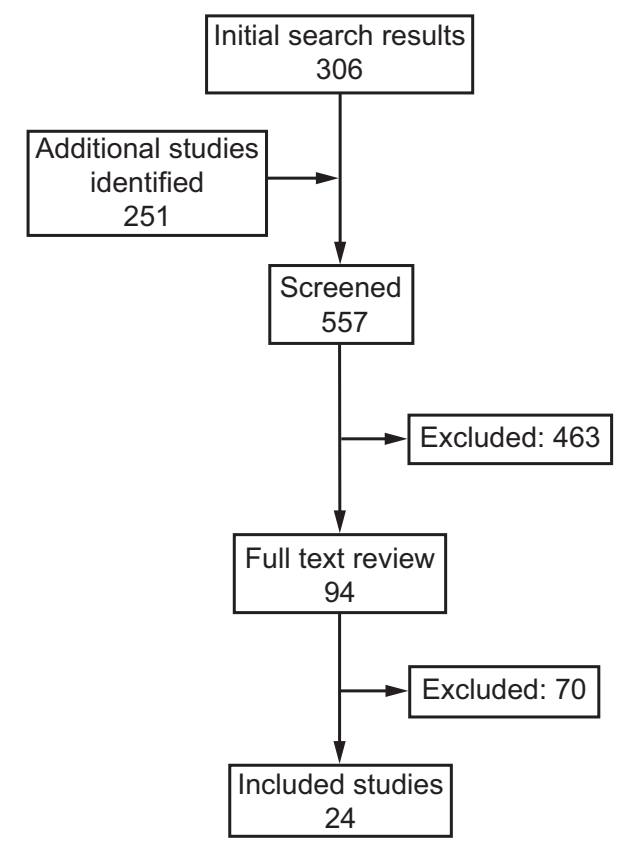

Fig. 1. Flow chart.

\section{Search Strategy}

We followed the Preferred Reporting Items for Systematic Reviews and Meta-Analyses (PRISMA) statement for this review. A literature review was performed via PubMed and Scopus databases to identify English-language studies related to our stated purpose. A manual search was performed on the bibliographic references of the selected articles to identify other relevant publications. The searches were last updated on February 27, 2019. All authors participated in evaluation of literature. The flow chart of the search is represented in Figure 1, and the full search strategy is available in Appendix 1 (see the supplementary materials at http://www.rcjournal.com).

\section{Why Is This a Problem?}

As the proliferation of technology in health care settings continues, so does the number of alarms related to these devices. Audible mechanical ventilator alarms such as high breathing frequency or high peak pressures can occur with relative frequency and short duration for patients who are more awake and mobile in the critical care setting. Staff exposure to large numbers of mechanical ventilator alarms, which may self-correct and are nonactionable, may result in a longer response time the next time the ventilator alarm sounds. ${ }^{15}$

Few studies have been published that measure both the quantity and categorization of ventilator alarms in relation to physiologic alarms. In 1999, Chambrin et al ${ }^{7}$ evaluated the number of types of alarms triggered per hour in 5 dif- 


\section{Mechanical Ventilation Alarms and Alarm Fatigue}

ferent ICUs (2 ICUs were located in university hospitals, and 3 were classified as general hospitals). The investigators reported that $37.8 \%$ of all alarms were generated by mechanical ventilators. A 2009 study that spanned 4 months and recorded 34,827 alarms noted that $42.2 \%$ of alarms in a cardiac ICU were attributable to mechanical ventilation. ${ }^{16}$ Lawless $^{6}$ identified that $31 \%$ of all alarms in a pediatric ICU during a 7-d observation originated with the mechanical ventilator. Joshi et al ${ }^{17}$ studied the responsiveness of nurses to physiologic alarms in the neonatal ICU and identified that mechanical ventilator alarms comprised $11.7 \%$ of the 6,000 alarms recorded on video over $2,400 \mathrm{~h}$.

Drew et al ${ }^{11}$ measured audible physiologic alarms from 77 ICU beds over a 31-d period. They noted an average of 187 alarms per bed, per day. While they did not specifically measure mechanical ventilation alarms, they did note the frequency of breathing frequency and apnea alarms measured on physiologic monitors. Over that 31-d period, there was a total of 161,931 apnea or breathing frequency alarms, with an average of 79 alarms per bed, per day. Apnea alarms occurred on the physiologic monitors generated from ECG leads while the patient was known to be receiving mechanical ventilation. ${ }^{11}$

An even smaller number of studies have isolated the number and types of alarms in acute care settings specific to ventilators. A 2018 study by Cvach et al ${ }^{18}$ focused solely on describing the incidence of ventilator alarms in ICUs at their facility. The researchers collected ventilator alarm data in 3 different ICUs over an 18-d period. The ventilators studied in these 3 ICUs produced 10,905 alarms in $>1,555$ ventilator hours, for approximately 7 alarms per ventilator hour. The most common alarms identified in this study included increased peak inspiratory pressure (34.3\%), increased breathing frequency (17.8\%), and low expired mandatory tidal volume $(12.9 \%)$. In a case report regarding mechanical ventilation alarm middleware technology, Dills ${ }^{19}$ estimated the number of ventilator alarms in a single, long-term acute care facility. They reportedly managed 100 mechanical ventilation patients per day, resulting in approximately 19,000 ventilator alarms per day (ie, approximately 190 per patient, per day).

Ventilator alarms are often considered among the highest-risk alarms in health care facility policies. Both morbidity and mortality related to ventilator alarm management have been reported by the FDA in their Manufacturer and User Facility Device Experience (MAUDE) database. ${ }^{20,21}$ A 2016 analysis of ventilator events reported to the FDA in the MAUDE database indicated that alarm interpretation and response was one of 3 major categories of reported events. ${ }^{21}$ Although $90 \%$ of the events reported in the MAUDE database did not result in harm, the risk of one missed ventilator circuit occlusion or disconnect could result in permanent harm or death for patients. In the home setting, the guideline by Sterni et $\mathrm{al}^{5}$ specifically recog- nizes caregiver burden secondary to false alarms - potentially, alarm fatigue - as a lesser issue than ensuring patient safety.

Variation in mechanical ventilation devices, terminology, modes, and features complicates the management of alarm response. In a single clinical setting, providers, nurses, and respiratory therapists may interact with ventilators of various ages, types, and manufacturers, and each may use different terminology for visual alerts and sounds for audible alarms. The use of noninvasive mechanical ventilation devices and modes present their own unique challenges. A noninvasive mechanical ventilator's lowpressure alarm may be of equal priority to that of an invasive mechanical ventilator, but the device may not have the same tone or audibility as the device delivering invasive therapy. In addition, the devices may interface differently with secondary alarm-notification devices or central monitoring systems. Variations in clinician discipline and experience with mechanical ventilation may also be a contributing factor in the ability to interpret and manage alarms. ${ }^{22}$ Development of a standard method for the assessment, troubleshooting, and response to ventilator alarms may be confounded by this lack of standardization.

\section{Issues With Setting Alarm Limits}

Mechanical ventilator technology has advanced, introducing new setting options associated with added visual alerts and audible alarms. Mechanical ventilators can monitor for changes in airway pressure, volume, and breathing frequency. Many variables affect these monitored parameters, such as changes in patient lung mechanics, patientventilator synchrony, and level of sedation or analgesia. Alarms generated by these parameters may require an audible alarm and immediate intervention, such as a ventilator circuit disconnect alarm. On the other hand, many alarms may not require immediate clinical intervention, such as high breathing frequency or high pressure, and these conditions may self-correct. For these types of alarms, an alert message and trending over time may be sufficient for monitoring purposes rather than an audible alarm. Clinicians may have difficulty making decisions about how to place delays for alarms, widen parameter settings, or disable parameters due to a lack of evidence-based best practices specific to for mechanical ventilator alarms.

Given the potential variables that may affect the strategy for supporting a patient on mechanical ventilation, the most appropriate way to set and manage mechanical ventilation alarms is still unknown. To our knowledge, there are no accepted standards regarding mechanical ventilation alarm parameters, monitoring frequency, and response expectations. It is logical to expect that both invasive and noninvasive ventilator alarms should be appropriately adapted to the needs of the patient. ${ }^{23,24}$ As previously stated, 
The Joint Commission has included alarm safety as a National Patient Safety Goal. ${ }^{2}$ Although organizations have heightened their level of concern surrounding mechanical ventilation alarm management, standards and guidelines are needed to achieve safe and effective practices regarding mechanical ventilation alarms. The interface between clinical disciplines such as nursing, respiratory care, and pulmonary critical care in setting therapeutic goals and responding to mechanical ventilator alarms should also be examined.

\section{Issues With Audible Alarms}

Mechanical ventilators, similar to other medical equipment and monitors, are furnished with audible and visual alert features. When both the audible and visual options are available, these alerts often occur together: a specific tone will sound while a flashing light will initiate on the machine. Depending on the level of the alert (ie, high, medium, or low priority), the mechanical ventilator may emit varying tones. The intent of the audible tones is to provide the clinician with an indicator that draws their attention to the flashing lights and the patient's condition. While the addition of an audible alert can be an effective way to alert the clinician to a change in status or adverse patient reaction, audible alerts have been identified as major sources of noise in the ICU. ${ }^{25}$ Frequent noise from these audible alerts may contribute to the issue of overall alarm fatigue.

\section{Negative Impact of Noise}

The purpose of the audible alert is to draw attention to the machine and its message for the clinician. However, the noise level created by the alert can be excessive. Sound intensity is measured in decibels. Both the World Health Organization (http://www.who.int/mediacenter/news/releases/ 2015/ear-care/en/, Accessed January 3, 2019) and the Occupational Safety and Health Administration (https:// www.osha.gov/pls/oshaweb/owadisp.show_document? table $=$ STANDARDS\&p_id=9735, Accessed January 3, 2019) recommend limited indoor exposure to occupational noise of $85-90 \mathrm{dBA}$ to a maximum of $8 \mathrm{~h} / \mathrm{d}$. The World Health Organization estimates that $16 \%$ of disabling hearing loss in adults can be due to occupational noise exposure. ${ }^{26} \mathrm{In}$ a review of literature, $\mathrm{Cvach}^{27}$ noted that studies revealed that the alarms of most medical intervention equipment exceeds $70 \mathrm{dBA}$. Tegnestedt et $\mathrm{al}^{28}$ recorded ventilator alarm sounds at $82 \mathrm{dBA}$ and $83 \mathrm{dBA}$. Although health care clinicians are not exposed to continuous alarms at $\geq 70 \mathrm{dBA}$ for the entirety of the work shift, studies indicate that mechanical ventilation alarms can be as frequent as 9 alarms/bed/h, ${ }^{19}$ and physiologic alarms can be as frequent as 7.8 alarms/bed/h. ${ }^{11}$ Extended exposure to this noise level can put additional stress on clinicians and contribute to feelings of fatigue, lack of concentration, and tension headaches. In addition, the consistent and loud noise levels can disrupt patient sleep.9,27-29 In their study of alarms in a neonatal ICU, Belteki and Morley ${ }^{30}$ noted that the infants were subjected to an average of 10 audible alarms/h/infant. Although most alarms recorded lasted $<1 \mathrm{~min}$, the study noted that some infants were subjected to audible alarms for $10 \%$ of the day, which may negatively affect recovery and neurodevelopment. ${ }^{30,31}$ In addition, this contributes to feelings of fear and anxiety in patients and visitors. ${ }^{27}$

\section{Factors Contributing to Alarm Fatigue}

As noted previously, alarm fatigue is a phenomenon that occurs as clinicians become desensitized to alarms due to their frequency and variety, resulting in decreased alertness and lower confidence in the accuracy and urgency of alarms. The primary factor contributing to alarm fatigue is the frequency of alarms generated in a patient care unit. Several studies have demonstrated that the audible alarm burden is substantial and concerning.7,8,11,19 Researchers have identified that the false-alarm- or provider-induced burden can be as high as $95 \% .{ }^{8}$ The audible burden can lead to a decreased alertness of health care professionals and alarm fatigue.

Over time, health care professionals who are exposed to significant volume and frequency of alarms may subconsciously ignore the sounds. Prior research has discovered that people rapidly learn to ignore frequent noises..$^{15}$ Therefore, frequent alarms, both actionable and nonactionable, contribute to the large number of alarms generated and may eventually be ignored. Some facilities may also institute a secondary alarm notification to ensure that alarms are not missed. ${ }^{32-34}$ Although well intended, this doubles the number of alerts generated for a single patient event, adding to the audible alert burden and perhaps hastening the learned behavior and alarm fatigue.

Another factor that can lead to alarm fatigue is the actual sound produced by the machines. Because there is no standardization in alarm tones for various alerts, ${ }^{32}$ manufacturers may not audibly differentiate between high alerts and low alerts. Drew et al $^{11}$ reported that $88.8 \%$ of arrhythmia alarms were false positives; however, the tone of the nonactionable alarm on that particular monitor was the same as an actionable alarm. Therefore, an increased number of nonactionable alerts increases the audible exposure to health care professionals, which decreases the likelihood the actionable alert is recognized and addressed in a timely manner. 


\section{Mechanical Ventilation Alarms and Alarm Fatigue}

\section{Recommendations for Future Research}

This review illustrates the paucity of published research that pertains to mechanical ventilation alarms. As stated earlier, several variables may impact the lack of literature, including the lack of standardization and sensitivity of both acute care and long-term mechanical ventilator alarms. To assure evidence-based practices pertaining to mechanical ventilation alarm practices, it is imperative that research be done to inform those practices.

Recommendations:

1. Identify ways for mechanical ventilation alarms systems to notify clinicians if an immediate response is necessary.

2. Identify alarm parameters that offer the safest level of monitoring while simultaneously reducing nuisance alarms that may contribute to alarm fatigue.

3. Identify efficient and effective ways of alerting clinicians to actionable alarms when they are not at the patient's bedside.

4. Identify gaps in knowledge and competencies needed for practitioners, professional caregivers, or family members responsible for responding to mechanical ventilation alarms.

5. Assess variation in noninvasive and invasive mechanical ventilators and develop strategies for clinicians to identify critical alarms that may be unique to that device or mode.

With information provided by studies addressing the areas of research listed above, clinicians can make evidence-based decisions regarding appropriate ventilator alarm settings and alerts appropriate for the patient's condition while minimizing the risk of alarm fatigue and negative patient outcomes.

\section{REFERENCES}

1. MacIntyre NR, Day S. Essentials for ventilator-alarm systems. Respir Care 1992;37(9):1108-1112.

2. The Joint Commission. Medical device alarm safety in hospitals. Sentinel Event Alert 2013;8(50):1-3.

3. Association for the Advancement of Medical Instrumentation. Creating a culture of safety: priority issues from the 2014 AAMI/FDA summit on ventilator technology. Arlington, VA: Association for the Advancement of Medical Instrumentation; 2014.

4. Kun SS, Nakamura CT, Ripka JF, Davidson Ward SL, Keens TG. Home ventilator low-pressure alarms fail to detect accidental decannulation with pediatric tracheostomy tubes. CHEST 2001;119(2): 562-564.

5. Sterni LM, Collaco JM, Baker CD, Carroll JL, Sharma GD, Brozek JL, et al. An official American Thoracic Society clinical practice guideline: pediatric chronic home invasive ventilation. Am J Respir Crit Care Med 2016;193(8):e35.

6. Lawless ST. Crying wolf: false alarms in a pediatric intensive care unit. Crit Care Med 1994;22(6):981-985.
7. Chambrin MC, Ravaux P, Cavelo-Aros D, Jaborska A, Chopin C, Boniface B. Multicentre study of monitoring alarms in the adult intensive care unit (ICU): descriptive analysis. Intensive Care Med 1999;25(12):1360-1366.

8. Görges M, Markewitz BA, Westenskow DR. Improving alarm performance in the medical intensive care unit using delays and clinical context. Anesth Analg 2009;108(5):1546-1552.

9. Siebig S, Kuhls S, Imhoff M, Gather U, Schölmerich J, Wrede CE. Intensive care unit alarms - how many do we need? Crit Care Med 2010;38(2):451-456.

10. Bonafide CP, Zander M, Graham CS, Weirich Paine CM, Rock W, Rich A, et al. Video methods for evaluating physiologic monitor alarms and alarm responses. Biomed Instrum Tech 2014;48(3):220-230.

11. Drew BJ, Harris P, Zègre-Hemsey JK, Mammone T, Schindler D, Salas-Boni $\mathrm{R}$, et al. Insights into the problem of alarm fatigue with physiologic monitor devices: a comprehensive observational study of consecutive intensive care unit patients. PloS ONE 2014;9(10):e110274.

12. Bridi AC, Louro TQ, da Silva RCL. Clinical alarms in intensive care: implications of alarm fatigue for the safety of patients. Rev Lat Am Enfermagem 2014;22(6):1034-1040.

13. Sendelbach S, Funk M. Alarm fatigue: a patient safety concern. Adv Crit Care 2013;24(4):378-386.

14. ECRI Institute. 2019 top 10 health technology hazards executive brief: a report from health devices. Plymouth Meeting, PA: ECRI Institute; 2018.

15. Bonafide CP, Lin R, Zander M, Graham CS, Paine CW, Rock W, et al. Association between exposure to nonactionable physiologic monitor alarms and response time in a children's hospital. J Hosp Med 2015;10(6):345-351.

16. Lipton JA, Vam Ettinger MJB, Barendse RJ, Van Dam TB, Van Der Putten NHJJ, Nelwan SP. Alarms on the intensive cardiac care unit. Comput Cardiol 2009;36:253-256.

17. Joshi R, Mortel HV, Feijis L, Andriessen P, Pul CV. The heuristics of nurse responsiveness to critical patient monitor and ventilator alarms in a private room neonatal intensive care unit. PLoS ONE 2017;12(10):e0184567.

18. Cvach MM, Stokes JE, Manzoor SH, Brooks PO, Burger TS, Gottschalk A, Pustavoitau A. Ventilator alarms in intensive care units: frequency, duration, priority, and relationship to ventilator parameters. Anesth Analg 2018 [Epub ahead of print] doi: 10.1213/ANE.0000000000003801

19. Dills CC. Managing mechanical ventilator alarms with middleware. Biomed Instrum Technol 2017;51(Suppl):62-65.

20. Love LC, Millin CJ, Kerns CD. Take precautions with audible alarms on ventilators. Nursing 2011;41(9):65.

21. Pham JC, Williams TL, Sparnon EM, Cillie TK, Scharen HF, Marella WM. Ventilator-related adverse events: a taxonomy and findings from 3 incident reporting systems. Respir Care 2016;61(5):621-631.

22. Strickland SL, Rodriquez D, Stampor J, Goodwin T, Hargett J, Papadakos P, Branson R. AARC issue paper: safe initiation and management of mechanical ventilation. Irving, TX: American Association for Respiratory Care; 2016.

23. Farré R, Navajas D, Prats E, Marti S, Guell R, Montserrat JM, et al. Performance of mechanical ventilators at the patient's home: a multicentre quality control study. Thorax 2006;61(5):400-404.

24. Branson RD, Brougher P, Chatburn RL, East TD, Marini JJ, MacIntyre NR. Consensus statement on the essentials of mechanical ventilators. Respir Care 1992;37(9):1000-1008.

25. Konkani A, Oakley B. Noise in hospital intensive care units: a critical review of a critical topic. J Crit Care 2012;27(5):522.e1-e9.

26. Nelson DI, Nelson RY, Concha-Barrientos M, Fingerhut M. The global burden of occupational noise-inducing hearing loss. Am J Ind Med 2005;48(6):446-458.

27. Cvach M. Monitor alarm fatigue: an integrative review. Biomed Instrum Technol 2012;46(4):268-277. 


\section{Mechanical Ventilation Alarms and Alarm Fatigue}

28. Tegnestedt C, Günther A, Reichard A, Bjurström R, Alvarsson J, Martling C-R, Sackey P. Levels and sources of sound in the intensive care unit: an observational study of three room types. Acta Anaesthesiol Scand 2013;57(8):1041-1050.

29. Salas RE, Gamaldo CE. Adverse effects of sleep deprivation in the ICU. Crit Care Clin 2008;24(3):461-476.

30. Belteki G, Morley CJ. Frequency, duration and cause of ventilator alarms on a neonatal intensive care unit. Arch Dis Child Fetal Neonatal Ed 2018;103(4):F307-F311.

31. Bergon-Sendin E, Perez-Grande C, Lora-Pablos D, De la Cruz Bertolo J, Moral-Pumarega MT, Bustos-Lozano G, Pallas-Alonso
$\mathrm{CR}$. Auditing of monitoring and respiratory support equipment in a level 3-c neonatal intensive care unit. Biomed Res Int 2015;15: 719497.

32. Stokes JE, Manzoor SH, Cvach MM. Ventilator alarms: challenges and opportunities for improvement. Biomed Instrum Tech 2017; 51(5):391-396.

33. Ruppel H, Funk M, Whittemore R. Measurement of physiological monitor alarm accuracy and clinical relevance in intensive care units. Am J Crit Care 2018;27(1):11-21.

34. Edworthy J, Hellier E. Fewer but better auditory alarms will improve patient safety. Qual Saf Health Care 2005;14(3):212-215. 